Indexed by

\section{Scopus}

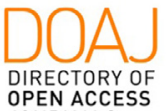

OPEN ACCESS

JOURNALS

Crossref

$\mathrm{R} \odot \mathrm{AD}$

KOBSON

\section{Djoko Adi Widodo}

Universitas Negeri Semarang,

Faculty of Engineering, Department of Electrical Engineering, Semarang, Indonesia

\section{Purwanto Purwanto}

Universitas Diponegoro,

Faculty of Engineering, Department of Chemical Engineering,

Semarang, Indonesia

\begin{abstract}
Hermawan Hermawan
Universitas Diponegoro, Faculty of Engineering, Department of Electrical Engineering, Semarang, Indonesia
\end{abstract}

Key words: artificial neural network, solar irradiance, solar energy potential, back propagation doi:10.5937/jaes0-29025

Cite article:

Widodo, D. A., Purwanto, P., Hermawan, H. (2021) MODELING SOLAR POTENTIAL IN SEMARANG, INDONESIA USING ARTIFICIAL NEURAL NETWORKS, Journal of Applied Engineering Science, 19(3), 578-585, DOI:10.5937/jaes0-29025

Online aceess of full paper is available at: www.engineeringscience.rs/browse-issues 


\title{
MODELING SOLAR POTENTIAL IN SEMARANG, INDONESIA USING ARTIFICIAL NEURAL NETWORKS
}

\author{
Djoko Adi Widodo 1*, Purwanto Purwanto², Hermawan Hermawan ${ }^{3}$ \\ ${ }^{1}$ Universitas Negeri Semarang, Faculty of Engineering, Department of Electrical Engineering, Semarang, Indonesia \\ ${ }^{2}$ Universitas Diponegoro, Faculty of Engineering, Department of Chemical Engineering, Semarang, Indonesia \\ ${ }^{3}$ Universitas Diponegoro, Faculty of Engineering, Department of Electrical Engineering, Semarang, Indonesia
}

Artificial neural network shows a good performance in predicting renewable energy. Many versions of Artificial Neural Network (ANN) models have been implemented to predict solar potential. This study aims to determine the monthly solar radiation in Semarang, Indonesia using ANN, and to visualize monthly solar irradiance as a map of the solar system of Semarang. This research applied the perceptron multi-layer ANN model, with 7 variables as input data of network learning, which were maximum temperature, relative humidity, wind speed, rainfall, longitude, latitude, and elevation. The input data set was obtained from a NASA normalized geo-satellite database website with a 5-year average daily score. Network training used backpropagation with one of the input layers, two of hidden layers, and one of the output layer. The performance of the model during the analysis of mean absolute percentage error was highly accurate (6.6\%) when 12 and 10 neurons were respectively installed in the first and second hidden layers. The result was presented in a monthly map of solar potential within the geographical information system (GIS) environment. The result showed that ANN was able to be one of the alternatives to estimate solar irradiance data. The sun irradiance map can be used by the government of Semarang City to provide information about the solar energy profile for the implementation of the solar energy system.

Key words: artificial neural network, solar irradiance, solar energy potential, back propagation

\section{INTRODUCTION}

Semarang is the fifth largest metropolitan city in Indonesia after Jakarta, Surabaya, Medan, and Bandung. As one of the developing cities on the island of Java, Semarang has a population of more than 1.7 million people. Semarang is a regional government center and the metropolitan city is committed to maintaining sustainable development, including the energy sector. The availability of clean and affordable energy is one of the sustainable development objectives. Fossil energy currently has become a global problem and issue that is why the efforts to provide clean energy have become the main attention of both central and local governments. In Indonesia, policy for new and renewable energies is set in Government Regulation No. 79 of 2014 on National Energy Policy. In the document, the new and renewable energies are targeted to reach $23 \%$ in 2025 , and a minimal $31 \%$ in 2050 . On the other hand, it is targeted that dependence on oil and coal will decrease by $20 \%$ and $25 \%$, respectively [1], [2].

Solar energy is considered to be one of the most promising renewable energy sources for meeting future energy needs. Solar energy has an important role in the global economy. The increasing use of fossil energy and other environmental problems makes solar energy an alternative energy source. Global solar radiation attains inland consists of direct radiation and diffuse radiation. The erratic characteristics of solar energy radiation bring limitations in the application of solar energy systems. Information about characteristic of solar energy and relevant meteorology parameter in one location plays an important role to learn, plan, and design solar energy application [3], [4]. For tropical areas such as Indonesia and specifically Semarang, it is very easy to find sunlight, but there is no reliable and calibrated solar irradiance measurement available in the local area. Artificial Neural Network is an intelligent system and used to overcome a complicated problem in many applications such as optimization, prediction, modeling, scheduling, categorization, pattern recognition, simulation, etc. Modeling or mapping of solar resources is an important part of the development, scheduling, and maintenance of the system, to determine the price of the right solar energy system [5]. Therefore, detailed knowledge of the characteristics of solar radiation is required to best exploit solar resources and the optimal operation and size of solar power plants. It is necessary to identify the prediction of solar radiation as one of the parameters in designing solar energy-based devices [6].

The machine learning technique now becomes the most popular method for predicting solar radiation. Special attention has been focused on the application of ANN methods, especially in the field of renewable energy for the prediction of meteorology data such as solar radiation [7]. Artificial Neural Networks (ANN) has been tested as a good correlation technique in several fields [8]. Its application to find the correlation between solar radiation and another climatology data has increased rapidly in the past because of its promising result so that some of the researchers conclude the benefit of its performance on other prediction methods [8]-[11]. Artificial Neural Networks as a method mostly used in the research predicting solar radiation consists of input and output layers, as well as 


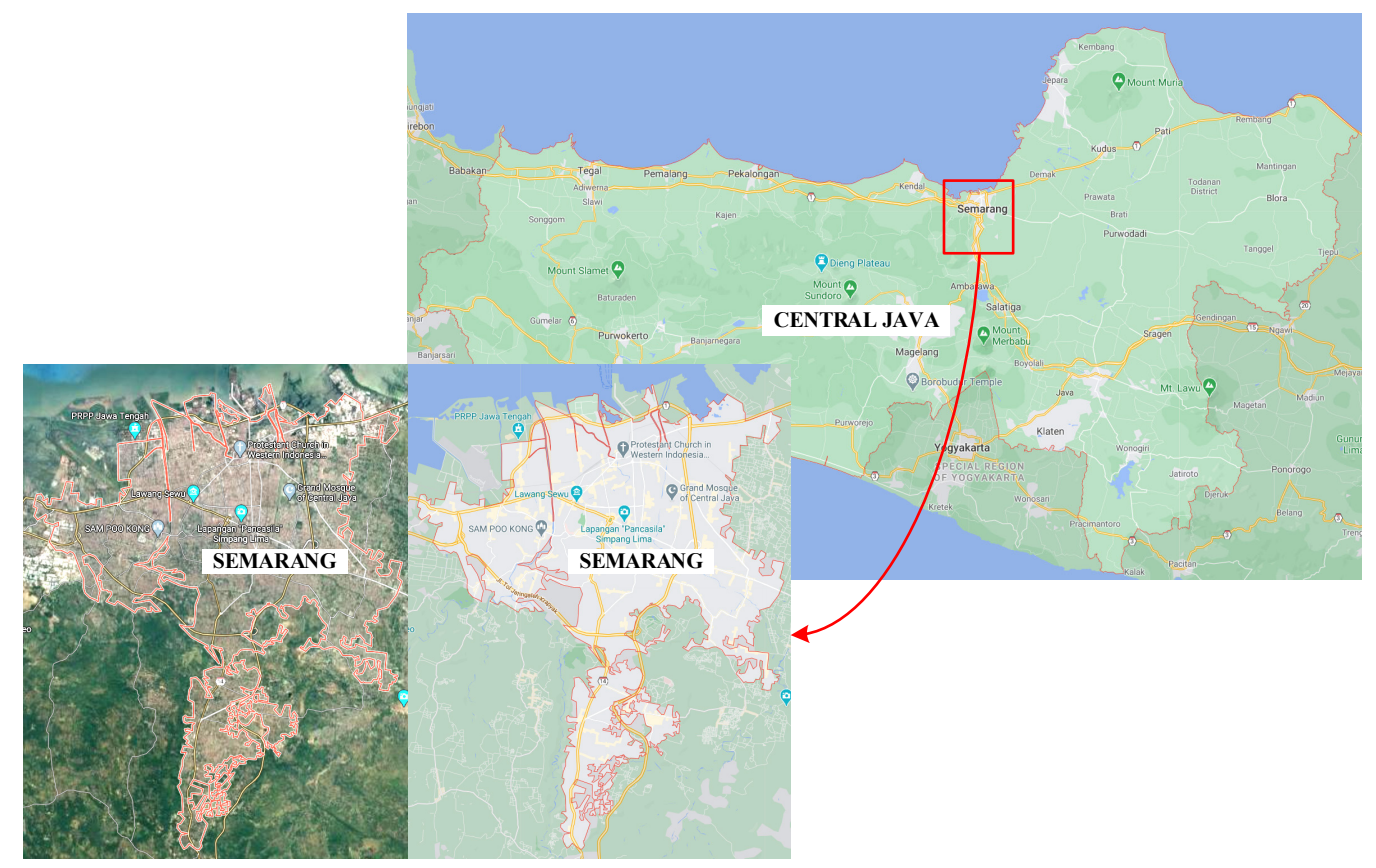

Figure 1: Geographical position of Semarang, Indonesia

one or more hidden layer(s) consist of units identified as neurons [12]. Bou-rabee et al., (2017) predict daily solar radiation in Kuwait using horizontal solar radiation data in five locations as ANN input variables [13]. In France, prediction of the global solar radiation is performed by Amrouche et al., (2014) using combination of ANN and spatial model with input variable in the form of weather data [14]. In Arabic, Assi et al., (2015) apply ANN with variable input of measured relative humidity, wind duration, sunlight and air temperature [15]. Alluhaidah et al., (2014) using some data of relative humidity, wind speed, wind direction, pressure, test cloud-cover, air temperature, and steam variables in Riyadh to obtain the most effective variable in predicting global solar radiation [16]. In India, Neelamegam et al., (2016) use latitude, longitude, altitude, year and month, average of air temperature, pressure, wind speed, and relative humidity data to estimate the average of monthly global solar irradiance [17]. The backpropagation algorithm from ANN modeling is considered the most suitable method to train a multi-layer feed-forward network. Artificial neurons are modeled as the process of multi-input non-linear with weighted interconnection [18], [19]. Ouammi et al., (2012), develop Artificial Neural Networks (ANN) to estimate monthly solar irradiance from 41 Moroccans. The data period used was from 1998 to 2010 and input for the network was normalized longitude, latitude, and elevation values. The predicted solar irradiance was varied from 5030 to $6230 \mathrm{Wh} / \mathrm{m}^{2} /$ day [19].

Geographical Information System (GIS) is a system that aims to capture, store, analyze, process, and present data related to location. In short, the GIS method is an amalgamation of database technology, cartography, and statistical analysis [20]. GIS Model has been used successfully in mapping solar radiation in several countries. Sozen et al. (2004) predict solar energy potential using ANN model and present solar energy monthly map to case study in Turkey [21]. Charabi et al. (2010) develop Oman's solar radiation map using GIS [22]. In Europe and the United States, GIS was used to develop all solar radiation atlases. GIS technology can be developed some renewable energy potentials, such as wind, hydro, biomass, and geothermal energy.

This research has a contribution to developing an artificial neural network model to estimate monthly solar irradiance potential in Semarang using satellite data. It proposes the development of solar energy mapping based on artificial neural network model prediction value using GIS technology. The solar irradiation map will be developed using the interpolation method with Inverse Distance Weighted (IDW) to obtain an accurate map. There has been no research about the potential for and mapping of solar irradiance in the local area in Semarang. Global solar radiation information is required for designing and estimate the solar energy performance of either photovoltaic or thermal systems. Semarang Meteorological Station conducts weather observations, one of which is solar radiation focusing on information and aviation services. Unfortunately, it is difficult for them to obtain solar irradiance data according to the location conditions for planning, implementing, and evaluating the potential for solar energy. To provide solutions to the problems, this research used satellite data for consideration of artificial neural network modeling to estimate solar irradiance.

\section{MATERIAL AND METHOD}

\section{Solar data collection}

Semarang is the fifth largest metropolitan city in Indonesia, located between $6^{\circ} 50^{\prime}-7^{\circ} 10^{\prime}$ south latitude and $109^{\circ} 35^{\prime}-110^{\circ} 50^{\prime}$ east longitude. The area recorded is $373.70 \mathrm{~km}^{2}$, consisting of $39.56 \mathrm{~km}^{2}(10.59 \%)$ of pad- 
dy fields and $334.14 \mathrm{~km}^{2}(89.41 \%)$ of non-paddy fields. Semarang has an altitude from 2 meters below sea level to 340 meters above sea level with a slope of $0 \%$ to $45 \%$. Its unique topographic conditions are narrow lowlands. Semarang receives solar energy almost evenly because of its geographic location, which is on the equator. The climate conditions are classified as tropical with the type of climate according to Koppen classification is Tropical Monsoonal. The data set and selected in this research consisted of a geographical parameter (latitude, longitude, altitude) and meteorological parameter (maximum temperature, wind speed, relative humidity, rainfall). Data were collected for 5 years, from 1st January 2015 to 31st December 2019. The data set were in the form of daily data, and the data were divided for network learning called as learning data and for network testing called as testing data, in which learning data was $80 \%$ (20152018 ) and testing data was $20 \%$ (2019). The data were collected from NASA's geo-satellite database website.

\section{Description of artificial neural network}

ANN method is an intelligent system that mimics the behavior of the basic elements of the human brain, the neuron. A series of identical artificial neurons are integrated into one another and become a neural network, as in the brain. Although the behavior of a single artificial neuron is relatively simple, the entire network can estimate complex system behavior in the multidimensional information domain [8]. There are several types of neural networks, however, almost all of them have the same components. Like a human brain, a neural network also includes several neurons and there are connections among these neurons. Those neurons will transfer information received from their exit connectors to other neurons. The information is kept in a particular value on the weight. The mostly used neuron model is based on McCulloch and Pitts that is shown in Figure 2.a [23]. Inspired by the biological concept, neuron artificial model is presented with $x_{1}, x_{2} \ldots x_{n}$ input representing electrical signals coming from other neurons. Because not all relevant input is the same; whether or not the neuron is active, so weight of $w_{1}, w_{2} \ldots w_{n}$ is determined for each input. Quantity $\theta$ is

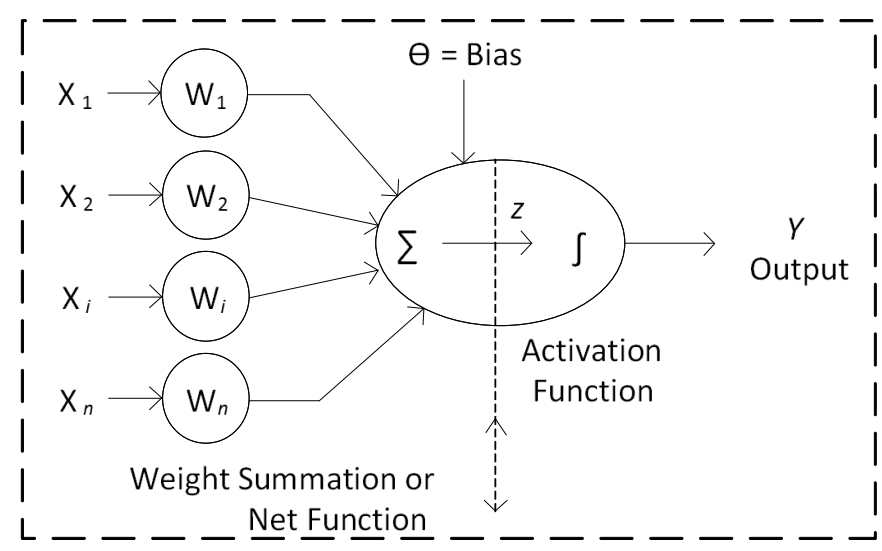

(a) known as bias and used to exemplify the adrenalin ability to lower the threshold. A neuron consists of two parts: net and activation functions. Net function determines how network input $\left\{x_{i}: 1 \leq i \leq n\right\}$ is combined in the neuron. The neuron model in figure 2.a was used to add input using a linear net function as in the following equation.

Parameter $\left\{w_{i}: 1 \leq i \leq n\right\}$ is known as synaptic weight. $z=\theta+\sum_{i=1}^{n} w_{i} x_{i}$

Quantity $\theta$ is called as bias (threshold) and it is used to model the threshold. Output from neuron, denoted by $y_{i}$, is related to network input $x_{i}$ through either linear or non-linear transformation called as activation function $y=f(z)$. In the Artificial Neural Network method, there are activation functions that can be applied, such as Unipolar Step, Bipolar Step, Unipolar Linear, Bipolar Linear, Unipolar Sigmoid, Bipolar Sigmoid, and Gaussian Radial Basis. However, the transfer function commonly used is Unipolar Sigmoid or Logistic due to its interesting, monotonicity, continuity, differentiability mathematical properties [23]. By using transfer function of Sigmoid or Logistic with linier net function, the y output of artificial neuron in figure 2.a can be simply written as in the following equation. After understanding the basic artificial neuron, the struc-

$$
y=\frac{1}{1+e^{-\left(\theta+\sum_{i=1}^{n} w_{i} x_{i}\right)}}
$$

ture of artificial neurons in the neural network can be defined as Artificial Neural Networks. Simple perceptron was the first Artificial Neural Network developed by Frank Rosenblatt acting as an electronic analog for the synaptic of human retina (Inman et al. 2013). Rosenblatt connects the perceptron input layer to the light sensor rectangular array. A directional graph from the simple perceptron network is shown in Figure 2. (b). Weight connecting input node $i$ to output node $j$ is denoted by the matrix component $w_{i j}$. The goal of Rosenblatt system is to trigger response units that are relevant to the presence of input pattern class. Input layer using unipolar linear transfer function is passed to the response layer through the weight that can be trained. The changes in

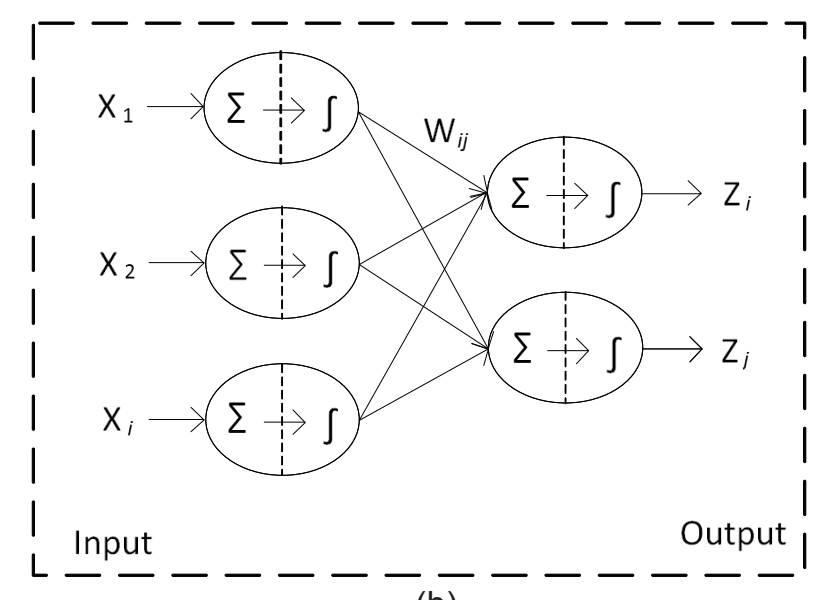

(b)

Figure 2: (a) Simple Model for Artificial Neuron; (b) Simple perceptron 
the weight matrix component $w_{i j}$ during the $n^{\text {th }}$ training set are given by the following equation.

$$
W_{i j}^{n}=\alpha\left(d_{j}^{n}-Z_{j}^{n}\right) X_{i}^{n}=\alpha \varepsilon^{n} X_{i}^{n}
$$

where $d_{i}^{n}$ is the output value becoming the target for input, $X_{i}^{n}, Z_{i}^{n}$ is the output value predicted from jth neuron and for $X^{n}$ input, $\varepsilon^{n}$ is the number of error for nth data set, $\alpha$ is the learning speed coefficient and after $n$ training set, so each $W_{i j}$ weight will be updated. To update the weight matrix $w$, the following equation was used

$w^{(n+1)}=w^{(n)}+\Delta w$

The result after $n$ training set was that each weight would be updated with the rule of perceptron learning. Optimization of perceptron learning can be carried out through $\alpha$ adjustment or learning speed coefficient.

\section{Design of the artificial neural network model}

This research developed the artificial neural network model to determine monthly global solar irradiance in Semarang. The process of designing an Artificial Neural Network was initiated by defining input, type of network, topology, training paradigm, and transfer function. The last step was validation where the ANN model was tested using a series of new data and its accuracy was evaluated using the statistical parameter. Figure 3.a presents the procedure of monthly global irradiance prediction using an Artificial Neural Network. The model was trained using geographical and meteorological data in Semarang (data collection for 5 years). Data were collected from January 2015 to December 2019. Data collected using parameters were different from Latitude, Longitude, Altitude, Temperature, Relative Humidity, Wind Speed, and Precipitation. The type of data was in the form of daily time-series data for 1825 days with a total of 7775 parameters. The data were divided into two parts, $80 \%$ for training data and $20 \%$ for testing data. The data were normalized using the mix-max method so that the data can be processed by ANN. Network architecture (Figure 3.b) used 7-12-10-1 structure (input layer with 7 neurons, output layer with 1 neuron, 2 hidden layers with 12 and 10 neurons). The learning algorithm used backpropagation. The activation function used was log sig - log sig - purelin. All methods were implemented using Matlab software. Login activation function in Matlab is known as the Sigmoid Biner activation function, while purelin activa-

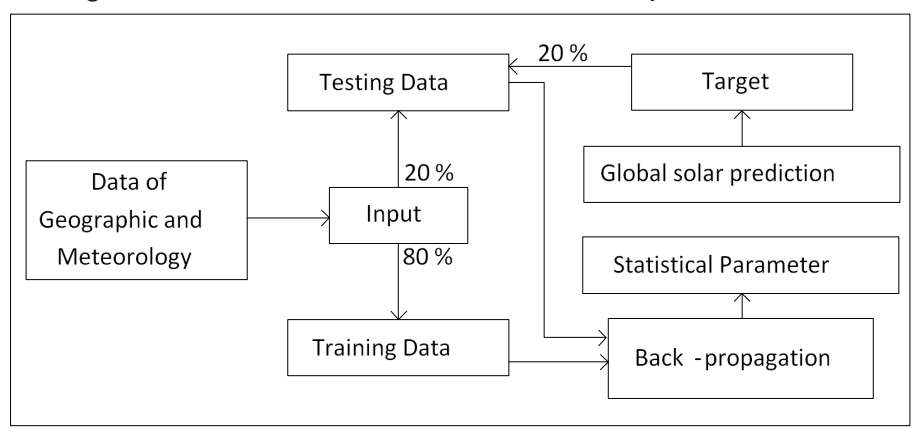

(a) tion function is known as a linear activation function.

Since the input variable is combined in ANN, according to Equation (1) and (2), both high and low input values can spoil the training phase. To avoid the problem, all input must be normalized before the training phase. Equation (5) presents normalization criteria [24].

$y=y_{\min }+\frac{x-x_{\min }}{x_{\max }-x_{\min }}\left(y_{\max }+y_{\min }\right)$

Where, $x$ is original data value and $y$ was the corresponding normalized variable. Then it can be assumed that $y_{\min }=-1$ and $y_{\max }=1$

Configuration of the neural network of multi-layer feed-forward (MLFF) was trained by Levenberg-Marquardt Back Propagation (LMBPL). As with other ANN training algorithm, the LMBPL training procedure consists of weight innovation $w_{i}$ and network $\theta$ bias based on the optimization of Levenberg Marquardt to meet the desired minimal modeling errors. To reach the error, the algorithm performs weight innovation and bias. Backpropagation training algorithm consists of three stages, which are: input the training data value to obtain output value; backpropagation from error value obtained; and adjust the connection weight to minimize error value (Fausett, 1994). These three stages were repeated continuously until the desired error target value was obtained. The prediction performance evaluation of the ANN model is adopted by the prediction accuracy index, namely MAPE (mean absolute percentage error), here is the equation:

$$
\text { MAPE }=\frac{1}{n} \sum_{i=1}^{n}\left|\frac{y_{i}-\hat{y}_{i}}{\hat{y}_{i}}\right|
$$

where, $y_{i}$ is the measured value or target, $\hat{y}_{i}$ is prediction value for monthly solar irradiance, while $\mathrm{n}$ is the number of data set analyzed.

MAPE value category refers to the indicator of mean absolute percentage error (MAPE), where MAPE $\leq 10 \%$ means that the prediction has a high accuracy, $10 \% \leq$ MAPE $\leq$ $20 \%$ means that the prediction is good, $20 \% \leq$ MAPE $\leq$ $50 \%$ means that the prediction is reasonable, and MAPE $\geq 50 \%$ means the prediction is not accurate [25]. MAPE is the most accurate method to calculate error because it states the percentage of error of the prediction result against the actual situation for certain period providing information whether the percentage is too high or too low.

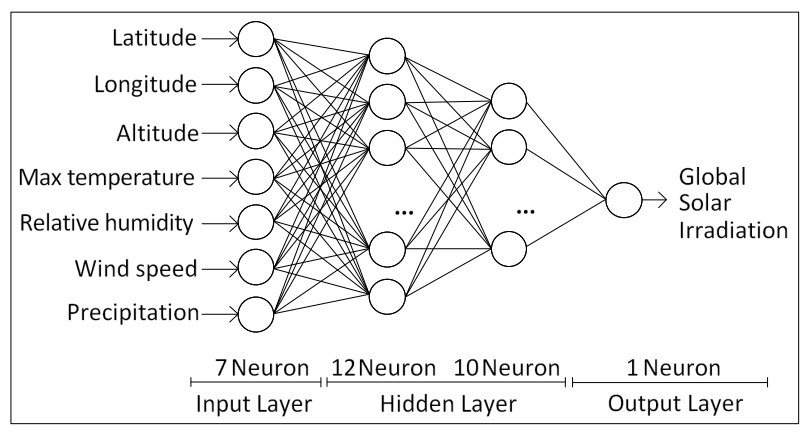

(b)

Figure 3: (a) Solar irradiance prediction model; (b) Network topology 


\section{RESULTS AND DISCUSSION}

\section{Solar irradiance prediction using ANN in Semarang}

In this study, Artificial Neural Networks were used to predict errors in designing training models. The neural network was able to recognize a pattern and produce an accurate input-output relationship. The analysis in this study uses a feed-forward propagation algorithm with two hidden layers. The number of neurons in the hidden layer is developed in this ANN method. Several structural efforts of MLP (Multi-layer Percepton) had been trained and developed in the Matlab software. MLP structure showed the number of neurons in all of the layers, included the input layer, hidden layer, and output layer. The comparison of the measured value and the predicted value was examined using statistical error (MAPE) with equation (6). ANN model had achieved significant suitability between an estimated value and measure value of the monthly average of global solar irradiance at an error of $6.6 \%$, under $10 \%$ and the accuracy of this prediction was high [25].

MAPE could be attained by an estimator with a structure of MLP, each of which consisted of 7 neurons in the input layer, 12 and 10 neurons in the first and second of hidden layers, respectively, and 1 neuron in the output layer.

The measured or target values and solar irradiance prediction for Semarang are presented in Table 1. The results of this study indicate a significant correlation in evaluating the potential for monthly solar radiation between measured and predicted values. This indicated that significant agreement between the measured and predicted values had been reached. ANN performance model in this research proved that the model was well functioned in predicting monthly solar irradiance potential in Semarang. The analysis showed that solar radia- tion in Semarang was different for each month. October is the month with the highest predicted value of solar radiation, while the lowest value is found in December. The highest error was found in March and the lowest was found in May. The monthly average prediction of solar irradiance was found to be $4,979 \mathrm{Wh} / \mathrm{m}^{2} /$ day. Figure 4 shows the factual and predictive value characteristics of solar irradiance from ANN analysis. This study succeeded in implemented the ANN model for a case study in Semarang by analyzing the variables of maximum temperature, humidity, wind speed, rainfall, longitude, latitude, and elevation in 5 years as a training and testing data to estimate the output of solar irradiance.

Table 1: Predictions of monthly solar irradiance mean obtained by AAN method

\begin{tabular}{|c|c|c|c|c|}
\hline Month & $\begin{array}{c}\text { Monthly } \\
\text { solar } \\
\text { irradiance } \\
\text { Wh/m²/day }\end{array}$ & $\begin{array}{c}\text { Monthly } \\
\text { solar } \\
\text { irradiance } \\
\text { predicted } \\
\text { Wh/m²/day }\end{array}$ & $\begin{array}{c}\text { Error } \\
\text { Wh/ } \\
\mathrm{m}^{2} / \text { day }\end{array}$ & $\begin{array}{c}\text { Error } \\
\%\end{array}$ \\
\hline January & 4,196 & 4,283 & 87 & 0.020 \\
\hline February & 4,431 & 4,267 & 164 & 0.039 \\
\hline March & 5,300 & 4,553 & 747 & 0.164 \\
\hline April & 5,102 & 4,529 & 573 & 0.126 \\
\hline May & 5,083 & 5,088 & 5 & 0.001 \\
\hline June & 4,806 & 4,304 & 502 & 0.117 \\
\hline July & 5,012 & 5,317 & 305 & 0.057 \\
\hline August & 6,004 & 5,904 & 99 & 0.017 \\
\hline September & 6,134 & 5,860 & 274 & 0.047 \\
\hline October & 6,145 & 6,685 & 540 & 0.081 \\
\hline November & 4,452 & 5,092 & 640 & 0.126 \\
\hline December & 3,964 & 3,859 & 105 & 0.027 \\
\hline Average & 5,053 & 4,979 & 337 & 0.07 \\
\hline
\end{tabular}

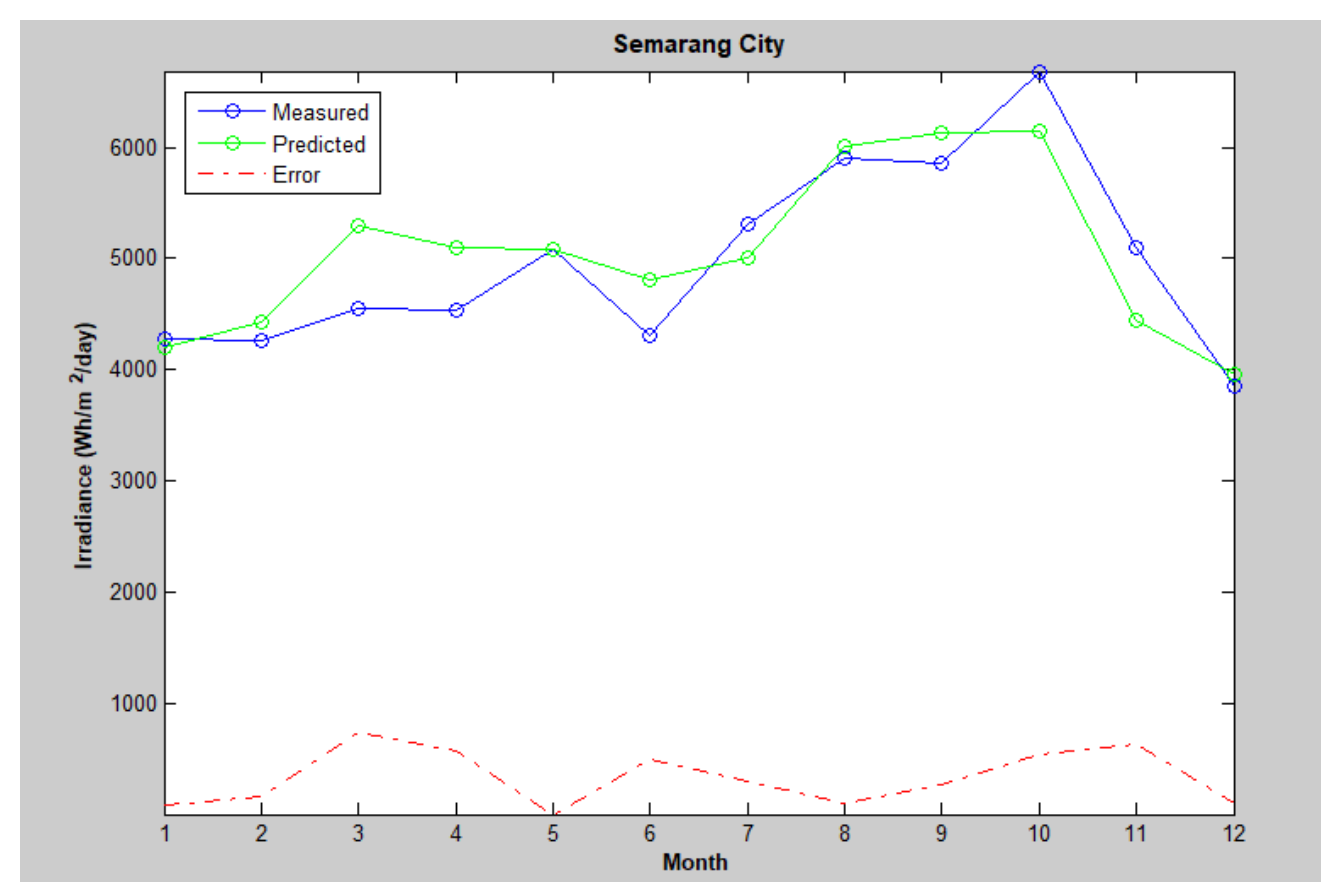

Figure 4: Comparison between measured and prediction 


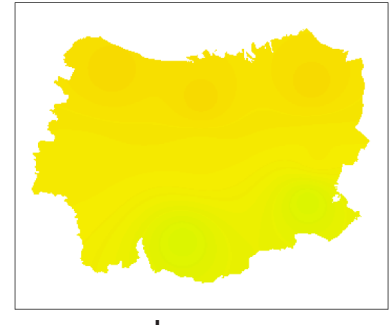

January

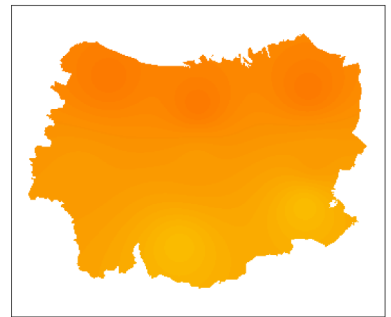

May

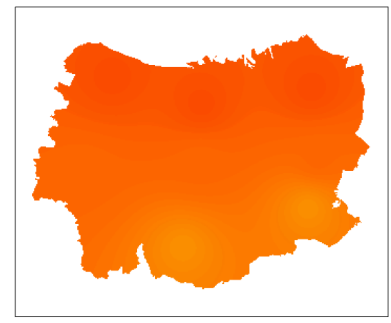

September

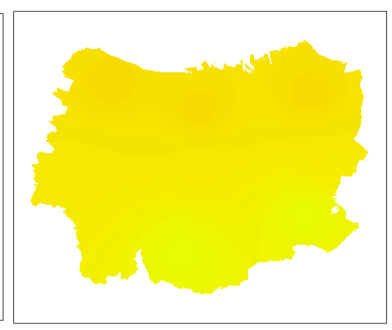

February

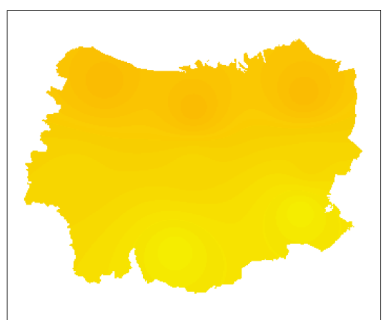

June

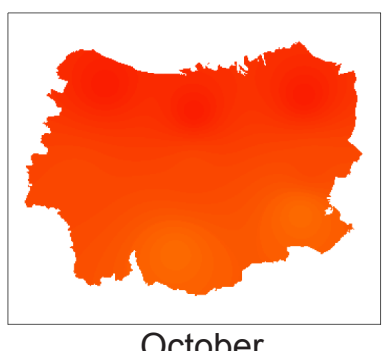

October

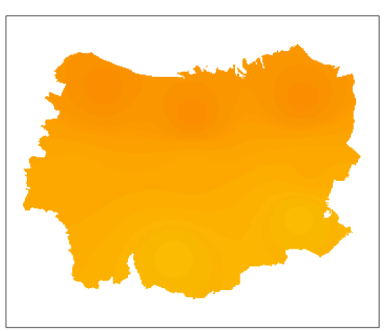

March

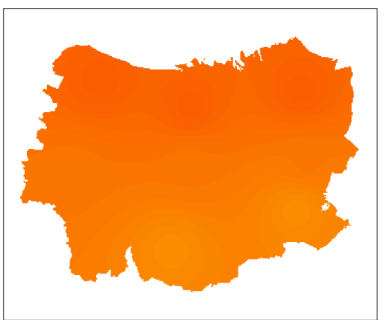

July

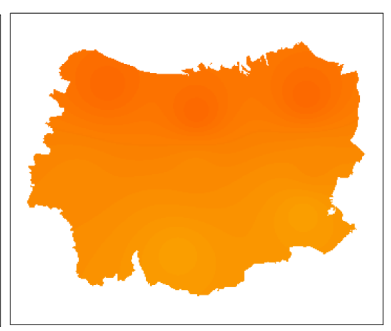

November

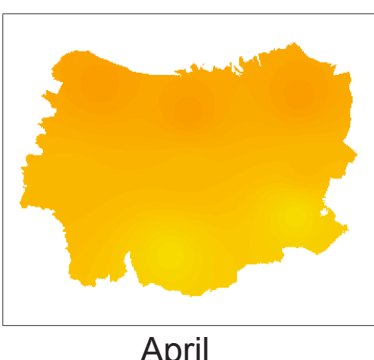

April

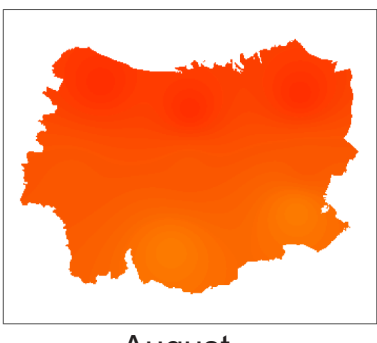

August

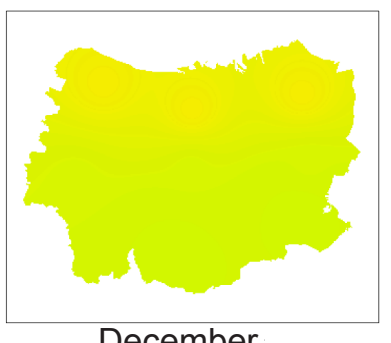

December

Monthly Solar Irradiance Maps
3800
4800

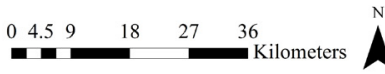

Figure 5: Solar irradiance map of Semarang as obtained by ANN with IDW technique

\section{Monthly solar irradiance mapping}

The value estimation of solar potential from the ANN model in this study is presented as a monthly map to obtain the spatial database. A Digital map of the Semarang city area with the availability of typical monthly solar energy is presented in Figure 5 on a scale of 1:200,000. The darkest color in the map shows the greatest potential for solar energy in that month.

The monthly solar irradiance can be used as an initial stage of decision making to get solar energy as a sustainable development project. This can be implemented as the basic literature to identify the potential for solar energy in Semarang. The map shows variation throughout the month in the research area at Semarang. Profile about the availability of solar irradiance reviewed according to the theoretical potential has been presented. As seen in the solar map, the availability of solar irradiance profiles can be used as a priority reference for the development of renewable energy. Semarang area has the potential for solar energy in 3 categories. Solar energy systems throughout the year, January, February, and December are included in the adequate category; March, April, May, June are included in the moderate category; while July, August, September, October, November are included in the high category. It shows that Semarang has significant potential for solar energy in 5 months.

By mapping the average of solar irradiance in a monthly period within one year, the solar energy decision-makers and engineers can obtain insight from the profile and learn the theoretical potential for the availability of solar irradiance. However, in exploitation, there will always be obstacles such as land use, geographic area, and economic conditions. Besides, the application of solar energy technology was limited by various factors. Therefore, the technical and economic potential of solar energy for a particular location and technology system needs further research.

\section{CONCLUSION}

ANN modeling was successfully developed in this research to estimate the solar radiation potential in Semarang. The potential for solar energy has succeeded. Presented in a monthly map using GIS technology where the source value is a prediction of ANN. The Inverse Distance Weighted method in a GIS environment has been successfully implemented in the process used to produce the solar maps presented in this study. By using GIS to visualize solar irradiance data, the final monthly 
solar map was obtained and it provided useful information for the planning of renewable energy from the sun in the local area of Semarang. The first map is published and will be useful for engineers and decision-makers in developing solar energy systems. This is a step to increase sustainable development based on renewable energy, especially in a city like Semarang which geographically has a large potential for solar power.

\section{REFERENCE}

1. Semarang Central Statistics Agency, "Semarang Municipality in Figures 2018," 2018.

2. Indonesia, "Blueprint Pengelolaan Energi Nasional," 2006.

3. H. Kutucu., A. Almryad. (2016). Modeling of Solar Energy Potential in Libya using an Artificial Neural Network Model. IEEE First International Conference on Data Stream Mining \& Processing, pp. 356-359, DOI: 10.1109/DSMP.2016.7583575

4. P. Neelamegam., V. A. Amirtham. (2016). Prediction of solar radiation for solar systems by using ANN models with different back propagation algorithms. Journal of Applied Research and Technology, vol. 14, no. 3, pp. 206-214, DOI: 10.1016/j.jart.2016.05.001

5. D. A. Fadare. (2009). Modelling of solar energy potential in Nigeria using an artificial neural network model. Applied Energy, vol. 86, no. 9, pp. 14101422, DOI: 10.1016/j.apenergy.2008.12.005

6. A. Qazi., H. Fayaz., A. Wadi., R. Gopal., N. A. Rahim., W. Ahmed. (2015). The artificial neural network for solar radiation prediction and designing solar systems : a systematic literature review. Journal of Cleaner Production, vol. 104, pp. 1-12, DOI: 10.1016/j.jclepro.2015.04.041

7. O. N. Mensour., B. El Ghazzani., B. Hlimi., A. Ihlal. (2017). Modeling of solar energy potential in Souss-Massa area-Morocco using intelligence Artificial Neural Networks (ANNs). Energy Procedia, vol. 139, pp. 778-784, DOI: 10.1016/j.egypro.2017.11.287

8. E. F. Alsina., M. Bortolini., M. Gamberi., A. Regattieri. (2016). Artificial neural network optimisation for monthly average daily global solar radiation prediction. Energy Conversion and Management, vol. 120, pp. 320-329, DOI: 10.1016/j.enconman.2016.04.101

9. T. Khatib., A. Mohamed., K. Sopian., M. Mahmoud. (2012). Assessment of Artificial Neural Networks for Hourly Solar Radiation Prediction. International Journal of Photoenergy, vol. 2012, DOI: 10.1155/2012/946890

10. M. Demirtas., M. Yesilbudak., Sagiroglu. (2012). Prediction of solar radiation using meteorological data. Proc Int Conf on Renewable Energy Research and Applications, Nagasaki, Japan 2012, pp. 1-5, DOI: 10.1109/ICRERA.2012.6477329
11. A. N. Celik., T. Muneer. (2013). Neural network based method for conversion of solar radiation data. Energy Convers Manage, vol. 67, no. 1, pp. 17-24, DOI: doi.org/10.1016/j.enconman.2012.11.010

12. S. Pereira., P. Canhoto., R. Salgado., M. João. (2019). Development of an ANN based corrective algorithm of the operational ECMWF global horizontal irradiation forecasts. Solar Energy, vol. 185, pp. 387405, DOI: doi.org/10.1016/j.solener.2019.04.070

13. M. Bou-rabee., S. A. Sulaiman., M. S. Saleh., S. Marafied. (2015). Using artificial neural networks to estimate solar radiation in Kuwait. Renewable and Sustainable Energy Reviews, vol. 72, pp. 434-438, DOI: 10.1016/j.rser.2017.01.013

14. B. Amrouche., X. Le Pivert. (2014). Artificial neural network based daily local forecasting for global solar radiation. Applied Energy, vol. 130, pp. 333-341, DOI: 10.1016/j.apenergy.2014.05.055

15. A. Assi., M. Al Shamisi., M. Jama. (2015). Prediction of Monthly Average Daily Global Solar Radiation in Al Ain City - UAE Using Artificial Neural Networks. Advances in Energy Planning, Environmental Education and Renewable Energy Sources.

16. B. M. Alluhaidah., S. leee., S. H. Shehadeh., S. leee., F. leee. (2014). Most Influential Variables for Solar Radiation Forecasting Using Artificial Neural Networks. 2014 Electrical Power and Energy Conference, pp. 71-75, DOI: 10.1109/EPEC.2014.36

17. P. Neelamegam., V. Arasu. (2016). Prediction of solar radiation for solar systems by using ANN models with different back propagation algorithms. Revista Mexicana de Trastornos Alimentarios, vol. 14, no. 3, pp. 206-214, DOI: doi.org/10.1016/j.jart.2016.05.001

18. K. Ermis., A. Midilli., I. Dincer., M. A. Rosen. (2007). Artificial neural network analysis ofworld green energy use. Energy Policy, vol. 35, no. 17, pp. 31-43, DOI: 10.1016/j.enpol.2006.04.015

19. A. Ouammi., D. Zejli., H. Dagdougui., R. Benchrifa. (2012). Artificial neural network analysis of Moroccan solar potential. Renewable and Sustainable Energy Reviews, vol. 16, no. 7, pp. 4876-4889, DOI: 10.1016/j.rser.2012.03.071

20. M. Rumbayan., A. Abudureyimu., K. Nagasaka. (2012). Mapping of solar energy potential in Indonesia using artificial neural network and geographical information system. Renewable and Sustainable Energy Reviews, vol. 16, no. 3, pp. 1437-1449, DOI: 10.1016/j.rser.2011.11.024

21. A. Sozen., E. Arcaklioglu., M. Ozalp. (2004). Estimation of solar potential in Turkey by artificial neural networks using meteorological and geographical data. Energy Conversion and Management, vol. 45, pp. 3033-3052, DOI: 10.1016/j.enconman.2003.12.020 
22. Y. Charabi., M. Ben., H. Rhouma., A. Gastli. (2010). GIS-Based Estimation of Roof-PV Capacity \& Energy Production for the Seeb Region in Oman. 2010 IEEE International Energy Conference, vol. 2, pp. 41-44, DOI: 10.1109/ENERGYCON.2010.5771717

23. A. Mellit., Kalogirou. (2008). Artificial intelligence techniques for photovoltaic applications: A review. Progress in Energy and Combustion Science, vol. 34, pp. 574-632, DOI: 10.1016/j.pecs.2008.01.001Get rights and content
24. A. Mellit., A. M. Pavan. (2010). A 24-h forecast of solar irradiance using artificial neural networks: application for performance prediction of a grid-connected PV plant at Trieste, Italy. Solar Energy, vol. 84, no. 8, pp. 7-21, DOI: 10.1016/j.solener.2010.02.006

25. A. K. Yadav., S. S. Chandel. (2014). Solar radiation prediction using Artificial Neural Network techniques: A review. Renewable Energy, DOI: doi.org/10.1016/j. rser.2013.08.055 